\title{
Simulation of reactive power regulation of DFIG
}

\author{
Yingfeng Zhu*, Xiaosu Xie, Dong Yang, Song Gao, Weichao Zhang, Xunkui Yuan \\ State Grid Shandong Electric Power Research Institute, JiNan, 250003, China
}

\begin{abstract}
Doubly fed induction generator (DFIG) wind power generation system is widely used in wind farm all over the world. Reactive power can be generated both in grid-side converter and generator-side converter of DFIG. In this paper, working principle and control method of DFIG are introduced, and the reactive power limit of DFIG is derived, finally reactive power regulation is simulated in Simulink.
\end{abstract}

\section{Introduction}

Wind power has developed rapidly with the advantages of mature technology and low $\operatorname{cost}^{[1]}$, variable-speed constant-frequency power generation technology is the mainstream of wind power generation ${ }^{[2]}$, among the various variable-speed constant-frequency implementation schemes, the doubly fed variable-speed constant-frequency (DFVSCF) wind turbine using DFIG is currently the most widely used machine.

Dual PWM converters are mostly used to control high-power DFIG, bi-directional power flow can be realized using this kind of converter, to ensure the effective operation under sub-synchronous and supersynchronous states, the grid-side PWM converter is used to maintain a constant DC bus voltage in the middle of the converter, the grid-side voltage-oriented current vector control method is often used to control the gridside PWM converter. The rotor-side PWM converter is used to control the the active and reactive power output by the generator, the active power needs to follow the mechanical input power of the motor, and the reactive power needs to adjust the power factor of the output power according to the demand of the grid $^{[3]}$.

The stator and rotor of DFIG are both connected to the power grid, and the stator output is controlled by the rotor converter ${ }^{[4]}$, DFIG can not only reduce the converter capacity, but also have flexible and powerful reactive power regulation capabilities. The grid voltage can be adjusted by controlling the reactive power in the grid. As an important reactive power source, DFIG wind farms should play their due role in stabilizing the grid voltage and compensating reactive power.

\section{Introduction of DFIG operating principle}

The doubly-fed wind power generation system is mainly composed of a wind turbine system and a doubly-fed power generation system, The double-fed power generation system consists of a double-fed induction motor, a grid-side converter, a generator-side converter and its control and protection system, as shown in figure 1. Gearbox is connected to the blad hub, used to increase the speed of wind turbine. The generator is driven by gearbox, generator stator is connected to the grid, generator rotor is connected to the rotor side converter, and the rotor side converter is connected to the grid side converter through the DC bus, the grid side converter is connected to the generator stator and the grid.

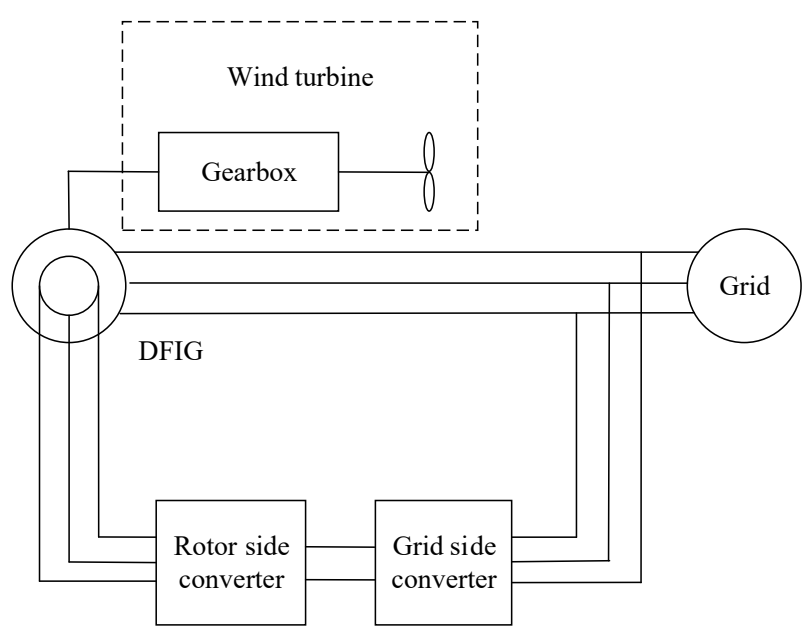

Figure 1 structure of doubly-fed wind power generation system

\subsection{Wind turbine}

Wind turbine is a component that converts wind energy into mechanical energy, it is used to obtain the kinetic energy generated in the sweeping range of the wind turbine blades and convert this part of the kinetic energy into mechanical energy, the effective output power of the entire wind power system depends on the wind turbine, and it is also one of the key components in the wind power system, which directly affects the safe and stable operation of the wind turbine.

The input power of the wind turbine can be expressed as,

"Corresponding author: yf_zhu@hotmail.com 


$$
P=\frac{1}{2} \rho A v^{3}
$$

Where $\rho$ is density of air, A is sweeping area of blade, and $\mathrm{v}$ is the wind speed.

The degree of absorption and utilization of wind energy by wind wheel can be expressed as $\mathrm{C}_{\mathrm{p}}$,

$$
C_{p}=\frac{P_{m}}{P_{w}}
$$

Where $P_{m}$ is output mechanical power of wind turbine, and $\mathrm{P}_{\mathrm{w}}$ is input power of wind turbine. $\mathrm{C}_{\mathrm{p}}$ is a function of tip speed ratio $\lambda$ and pitch angle $\beta$, and can be expressed as $\mathrm{C}_{\mathrm{p}}(\lambda, \beta)$. If the pitch angle $\beta$ remains unchanged, $\mathrm{C}_{\mathrm{p}}$ is only related to $\lambda$, For a certain type of wind turbine, $\mathrm{C}_{\mathrm{p}}$ can reaches the maximum value $\mathrm{C}_{\mathrm{pmax}}$ only when $\lambda$ equals $\lambda_{\mathrm{opt}}$, as shown in figure 2 ; if the tip speed ratio $\lambda$ remains unchanged, the $\mathrm{C}_{\mathrm{p}}$ curve obviously decreases with the pitch angle increasing, and $C_{p}$ can reaches the maximum value $\mathrm{C}_{\mathrm{pmax}}$ when pitch angle $\beta$ equals 0 .

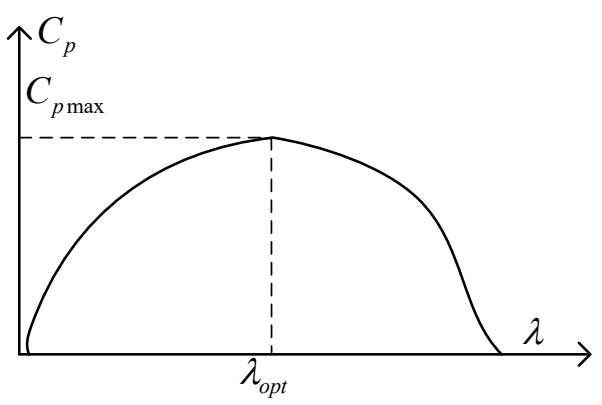

Figure 2 relationship between $C_{p}$ and $\lambda$

So the output power of wind turbine can be expressed as:

$$
P_{\mathrm{m}}=\frac{1}{2} C_{p} \rho \pi R^{2} v^{3}
$$

Where $\mathrm{R}$ is wind wheel radius of wind turbine.

This paper uses the equivalent model of two masses to study the transmission system of the wind turbine, the motion equations can be expressed as

$$
\begin{aligned}
& 2 H_{g} \frac{d \omega_{g}}{d t}=T_{r}-T_{e}-D_{g} \omega_{g} \\
& 2 H_{t} \frac{d \omega_{t}}{d t}=T_{m}-T_{r}-D_{t} \omega_{t} \\
& T_{r}=K_{r} \theta_{r}+\frac{d \theta_{r}}{d t} \\
& \frac{d \theta_{r}}{d t}=\left(\omega_{t}-\omega_{g}\right)
\end{aligned}
$$

Where $\mathrm{H}_{\mathrm{t}}, \mathrm{H}_{\mathrm{g}}$ represent the inertia constant of the wind turbine and generator rotor respectively, $\omega_{t}, \omega_{g}$ represent the electrical angular velocity of the wind turbine and generator rotor respectively, $D_{t}, D_{g}$ represent the damping coefficient of the wind turbine and generator rotor respectively, $\mathrm{D}_{\mathrm{r}}, \mathrm{K}_{\mathrm{r}}, \mathrm{T}_{\mathrm{r}}, \theta_{r}$ represent damping coefficient, stiffness coefficient, torque, angular displacement of transmission shaft between generator rotor and wind turbine.

\subsection{Control of grid-side converter}

The doubly-fed wind power generation system adopts a back-to-back connection structure of double converters. Due to its DC loop, two converters can be controlled independently, and at the same time, coordinated control can be carried out according to system operation requirements.

The control of the grid-side converter mainly includes two aspects: DC voltage control and AC current control. Dual-loop control is usually used, which contains voltage outer loop and power inner loop control. The voltage outer loop is used to maintain the constant voltage of DC link, and the power inner loop is used to control the magnitude and direction of the reactive power transmitted by the converter ${ }^{[5]}$.

The voltage and current equations of the converter under the dq axis can be expressed as

$$
\begin{aligned}
& L \frac{d i_{d}}{d t}=u_{d}-v_{d}-R i_{d}+\omega_{1} L i_{q} \\
& L \frac{d i_{q}}{d t}=u_{q}-v_{q}-R i_{q}-\omega_{1} L i_{d}
\end{aligned}
$$

Where $\mathrm{v}_{\mathrm{d}} \mathrm{v}_{\mathrm{q}}$ are $\mathrm{dq}$ axis voltage of grid-side converter's $\mathrm{AC}$ side, $\mathrm{u}_{\mathrm{d}} \mathrm{u}_{\mathrm{q}}$ are $\mathrm{dq}$ axis voltage of grid. From formula (5), $\mathrm{dq}$ axis voltage of grid-side converter's AC side are related to dq axis current, which is also related to grid voltage $\mathrm{u}_{\mathrm{d}} \mathrm{u}_{\mathrm{q}}$. To realize decoupling control of PWM converter, formula (5) should be transformed to

$$
\begin{aligned}
& v_{d}=u_{d}+\omega_{1} L i_{q}-L \frac{d i_{d}}{d t}-R i_{d} \\
& v_{q}=u_{q}-\omega_{1} L i_{d}-L \frac{d i_{d}}{d t}-R i_{q}
\end{aligned}
$$

Considering eliminating the cross-coupling item and feedforward item,

$$
\begin{aligned}
& v_{d}^{*}=-\left(k_{p}+\frac{k_{i}}{s}\right)\left(i_{d}^{*}-i_{d}\right)+\omega_{1} L i_{q}+u_{d} \\
& v_{q}^{*}=-\left(k_{p}+\frac{k_{i}}{s}\right)\left(i_{q}^{*}-i_{q}\right)-\omega_{1} L i_{d}+u_{q}
\end{aligned}
$$

Where $\mathrm{k}_{\mathrm{p}}, \mathrm{k}_{\mathrm{i}}$ are proportional and integration time constant of PI regulator, $v_{d}^{*} v_{q}^{*}$ are $\mathrm{dq}$ axis voltage reference value of converter's AC side, $i_{d}^{*} i_{q}^{*}$ are dq axis current reference value of converter's AC side. 
The active power and reactive power absorbed by the grid-side converter are,

$$
\begin{aligned}
& P_{g}=\frac{3}{2}\left(u_{d} i_{d}+u_{q} i_{q}\right) \\
& Q_{g}=\frac{3}{2}\left(u_{q} i_{d}-u_{d} i_{q}\right)
\end{aligned}
$$

When using grid voltage-oriented vector control, $\mathrm{u}_{\mathrm{d}}=\mathrm{u}_{\mathrm{s}}, \mathrm{u}_{\mathrm{q}}=0$, (8) can be transformed to

$$
\begin{aligned}
& P_{g}=\frac{3}{2} u_{s} i_{d} \\
& Q_{g}=-\frac{3}{2} u_{s} i_{q}
\end{aligned}
$$

So, by controlling $\mathrm{i}_{\mathrm{d}}$ and $\mathrm{i}_{\mathrm{q}}, \mathrm{P}_{\mathrm{g}}$ and $\mathrm{Q}_{\mathrm{g}}$ can be controlled. A positive $\mathrm{P}_{\mathrm{g}}$ means that the converter works in rectification state and absorbs energy from the grid; a negative $\mathrm{P}_{\mathrm{g}}$ means that the converter working in the inverter state, energy is fed back to the grid from the converter. A positive $\mathrm{Q}_{\mathrm{g}}$ means that the converter is inductive to the grid and absorbs inductive reactive power from the grid, a negative reactive power means that the converter is capacitive to the grid and absorbs capacitive reactive power from the grid.

\subsection{Control of generator-side converter}

Stator field orientation control is used in generator-side converter, the $\mathrm{d}$ axis is oriented to the space vector of the stator flux linkage, as shown in figure 3 . So

$$
\begin{array}{ll}
\psi_{s d}=\psi_{s} & \psi_{s q}=0 \\
u_{s d}=0 & u_{s q}=u_{s}
\end{array}
$$

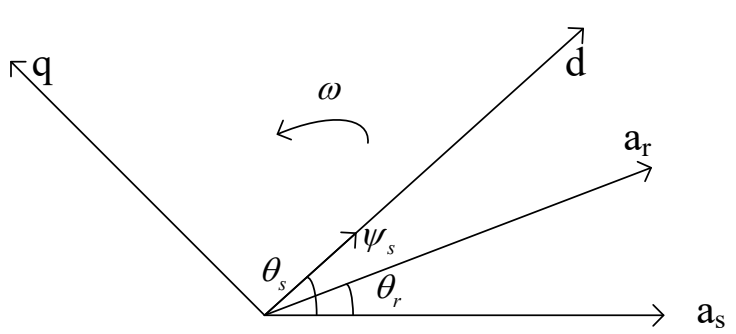

Figure3 position relationship of stator flux orientation

The active power and reactive power of generator are

$$
\begin{gathered}
P_{s}=\frac{3}{2} u_{s} i_{s q} \\
Q_{s}=\frac{3}{2} u_{s} i_{s d}
\end{gathered}
$$

Generator stator flux equation under dq axis can be expressed as,

$$
\begin{aligned}
& i_{s q}=\frac{L_{m}}{L_{s}} i_{r q} \\
& i_{s d}=\frac{L_{m}}{L_{s}} i_{r d}-\frac{1}{L_{s}} \Psi_{s}
\end{aligned}
$$

So, (11) can be expressed as,

$$
\begin{aligned}
& P_{s}=\frac{3}{2} u_{s} i_{s q}=\frac{3}{2} \frac{L_{m}}{L_{s}} u_{s} i_{r q} \\
& Q_{s}=\frac{3}{2} u_{s} i_{s d}=\frac{3}{2} u_{s}\left(\frac{L_{m}}{L_{s}} i_{r d}-\frac{1}{L_{s}} \frac{u_{s}}{\omega_{1}}\right)
\end{aligned}
$$

The motion equation under dq axis can be expressed as

$$
\begin{aligned}
& u_{r d}=R_{r} i_{r d}+\sigma \frac{d i_{r d}}{d t}-\omega_{s} \sigma i_{r q} \\
& u_{r q}=R_{r} i_{r q}+\sigma \frac{d i_{r q}}{d t}+\omega_{s} \sigma i_{r d}+\omega_{s} \frac{L_{m}}{L_{s}} \psi_{s}
\end{aligned}
$$

Where $\sigma=\left(L_{r}-\frac{L_{m}^{2}}{L_{s}}\right)$.

Corresponding cross-coupling items are designed for compensation and decoupling, so the dq axis currents of generator-side converter can realize true decoupling control, and the rotor current decoupling compensation term is designed as

$$
\begin{aligned}
& u_{r d}{ }^{*}=\left(k_{r p}+\frac{k_{r i}}{s}\right)\left(i_{r d}^{*}-i_{r d}\right)+\omega_{s}\left(L_{r}-\frac{L_{m}^{2}}{L_{s}}\right) i_{r q} \\
& u_{r q}{ }^{*}=\left(k_{r p}+\frac{k_{r i}}{s}\right)\left(i_{r q}^{*}-i_{r q}\right)-\omega_{s}\left(L_{r}-\frac{L_{m}^{2}}{L_{s}}\right) i_{r d}-\omega_{s} \frac{L_{m}}{L_{s}} \psi_{s}
\end{aligned}
$$

\section{3 simulation}

A 9 MW DFIG model in matlab/simulink is built to verify the control method. When the generator reactive power reference iqr* is changed from 0 to 0.3 , the output reactive power of generator changed following the reference, as shown in figure 4 . When the grid side converter reactive power reference iqg* is changed from -0.01 to 0.1 , the output reactive power of grid side converter changed following the reference, as shown in figure 5. So it's can be verified that the reactive power of generator can be controlled by iqr*, and the reactive power of generator can be controlled by iqg*. 


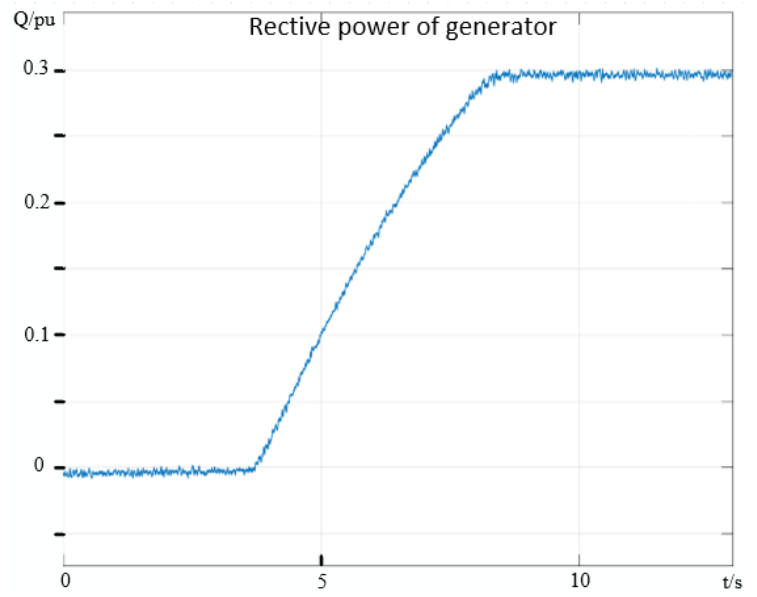

Figure 4 Regulation of generator's reactive power

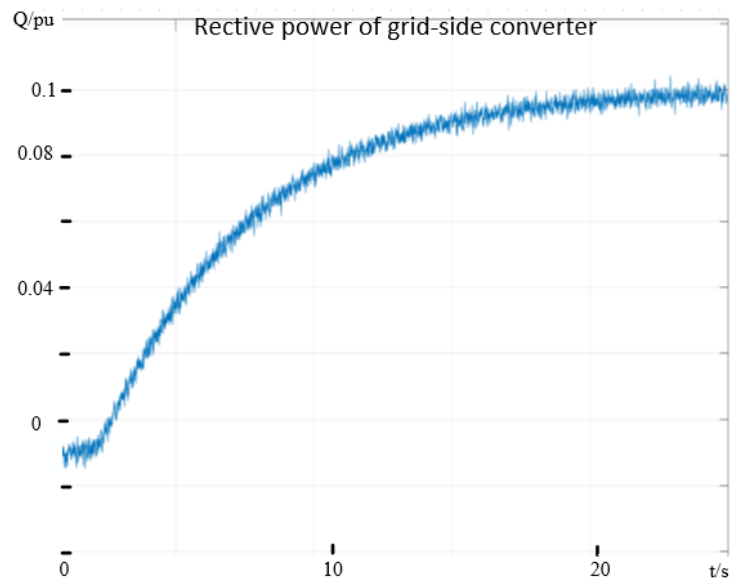

Figure 5 Regulation of grid-side converter's reactive power

\section{Acknowledgments}

The work described in this paper was fully supported by Science and Technology of State Grid Shandong Electric Power Company (NO. 520626190022).

\section{References}

1. Mihet-Popa L, Blaabjerg F, Boldea I. Wind turbine Generator modeling and Simulation where rotational speed is the controlled variable $[\mathrm{J}]$. IEEE Transaction on Industry Application, 2004,40(1):310.

2. Tapia G, Giovanna Santamar'1a, Mikel Telleria, et al. Methodology for smooth connection of doubly fed induction generators to the grid[J]. IEEE Transaction on Energy Conversion, 2009,24(4): 959-971.

3. Liu Sijia, Zhuang Shengxian, Shu Xindong. Power Control of DFIG in Stator Voltage Oriented Frame[J] Large Electric Machine and Hydraulic Turbine, 2010(04):38-41.

4. Liu Qihui. The investigation of operation and control for a variable speed constant frequency wind power generation system [D]. Hangzhou: Zhejiang University,2005.

5. Zhang Chongwei, Zhang Xing. PWM rectifier and control[M]. China Machine PRESS, 2003. 